\title{
Supplemental Information \\ Performance and Durability of Pure-Water-Fed Anion Exchange Membrane Electrolyzers Using Baseline Materials and Operation
}

\author{
Grace A. Lindquist, ${ }^{\dagger}$ Sebastian Z. Oener, ${ }^{\dagger}$ Raina Krivina, ${ }^{\dagger}$ Andrew R. Motz, ${ }^{\star}$ Alex Keane,, \\ Christopher Capuano, ${ }^{*}$ Katherine E. Ayers, ${ }^{+}$and Shannon W. Boettcher, ${ }^{*}+$ \\ †Department of Chemistry and Biochemistry and the Oregon Center for Electrochemistry, \\ University of Oregon, Eugene, Oregon 97403 \\ $\$$ Present: Department of Interface Science, Fritz-Haber Institute of the Max Planck Society, \\ Berlin, Germany, 14195 \\ tNel Hydrogen, Wallingford, Connecticut 06492 \\ *swb@uoregon.edu
}

\section{Additional notes on electrode coating}

The stainless-steel material has a graded porosity, so it is important the catalyst be coated on the layer with smaller pores (visually smoother side). When applying catalyst, the airbrush was held 5 to $8 \mathrm{~cm}$ from the hot plate and the catalyst was sprayed in short, even bursts of the airbrush to prevent any large droplets or catalyst aggregation. The hot plate was rotated every few sprays to ensure even coating. Slow coating was found essential, as the ink will soak into the bulk of the material if too wet and will result in an inconsistent top coating. Inks were sprayed in short bursts while waiting multiple (5-10) seconds between each burst. The solvent evaporation can be observed as the coating color changes from dark to light. Additional ink was not added until the previous layer was visually dry. A progression of coating a GDL is shown in Fig. S1 with an example of an electrode sprayed too quickly (Fig. S1e).

The $\mathrm{IrO}_{2}$ catalyst was found to be particularly difficult to disperse. The ink was sonicated until it was fully opaque and would remain on the side of the vial before dripping down when swirled or shaken. Videos showing poorly-dispersed (SI Video 1) and well-dispersed (SI Video 2) $\mathrm{IrO}_{2}$ inks are included. These visual indicators are not intended to be a quantitative determination of the solution dispersion, but rather a qualitative check that the catalyst is dispersed. The catalyst dispersion was periodically checked throughout coating. If catalyst was observed to collect at the bottom of the vial, the ink was sonicated an additional $\sim 60 \mathrm{~s}$ until re-dispersed. 


\section{$\underline{\text { Supplemental Figures }}$}
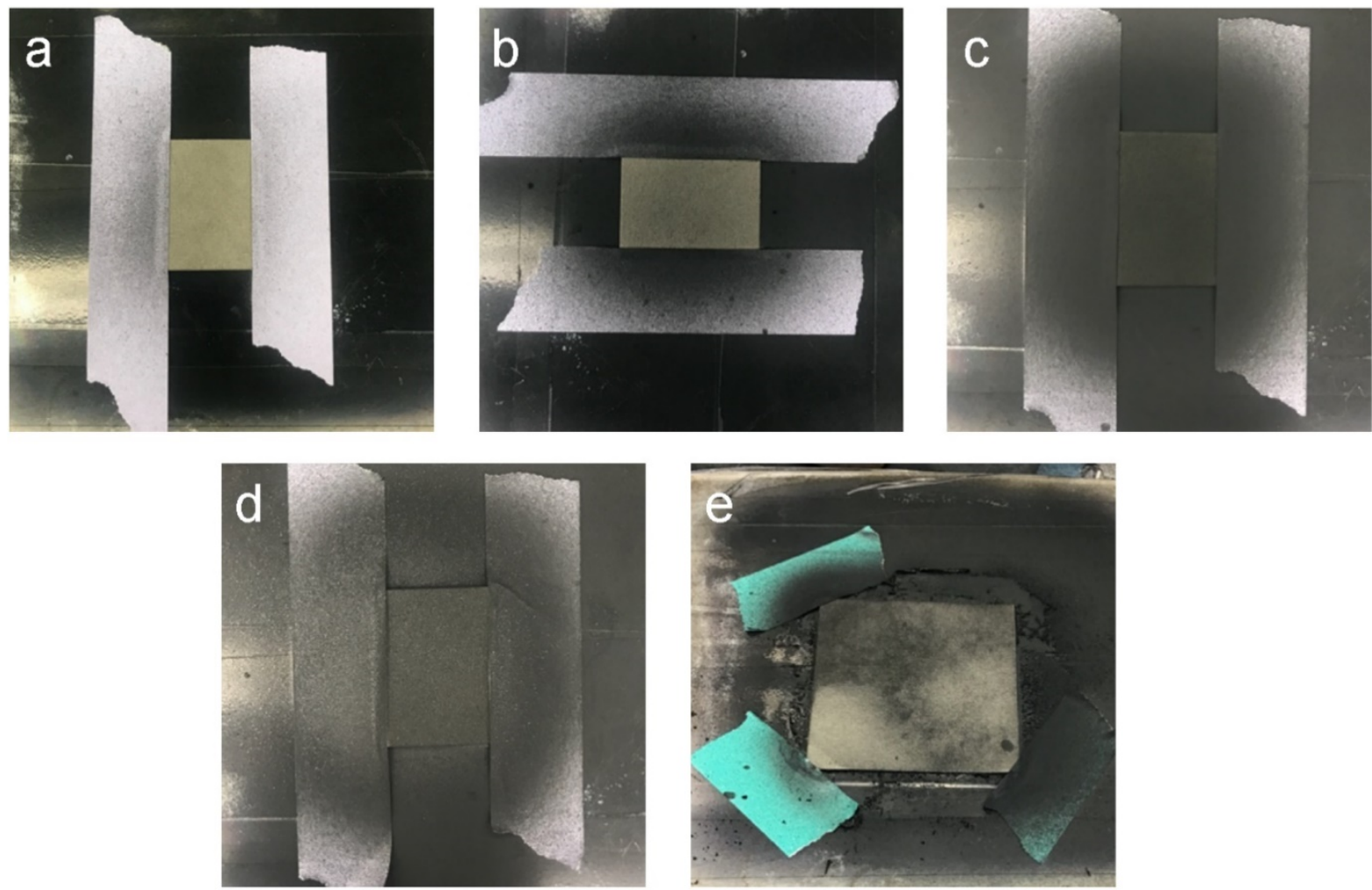

Figure S1: Progression of spray coating stainless-steel GDLs. a) The color starts very light. Continue spraying slowly, ensuring the ink dries between layers. b) The hot plate is rotated to ensure even coverage. The color will start to darken slowly. c) The GDL is similar color to the coated tape when full loading is achieved. d) A thin layer of ionomer solution is sprayed on top of the catalyst. e) If coating too quickly and the GDL gets too wet, the material pulls the ink into the bulk leaving bare surface. Even after continued spraying these areas will not coat.

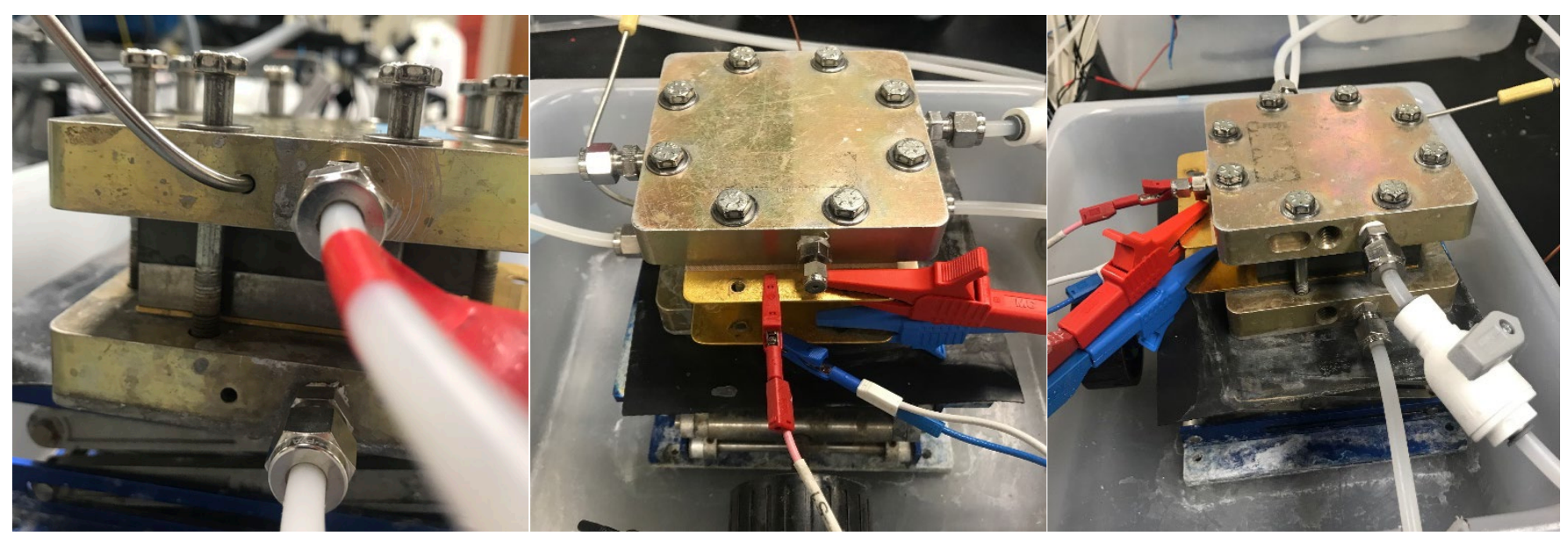

Figure S2: Electrolyzer photos including side view showing thermocouple insert for monitoring temperature in the electrolyzer. The thermocouple is placed in the outer hardware on the cathode side. 

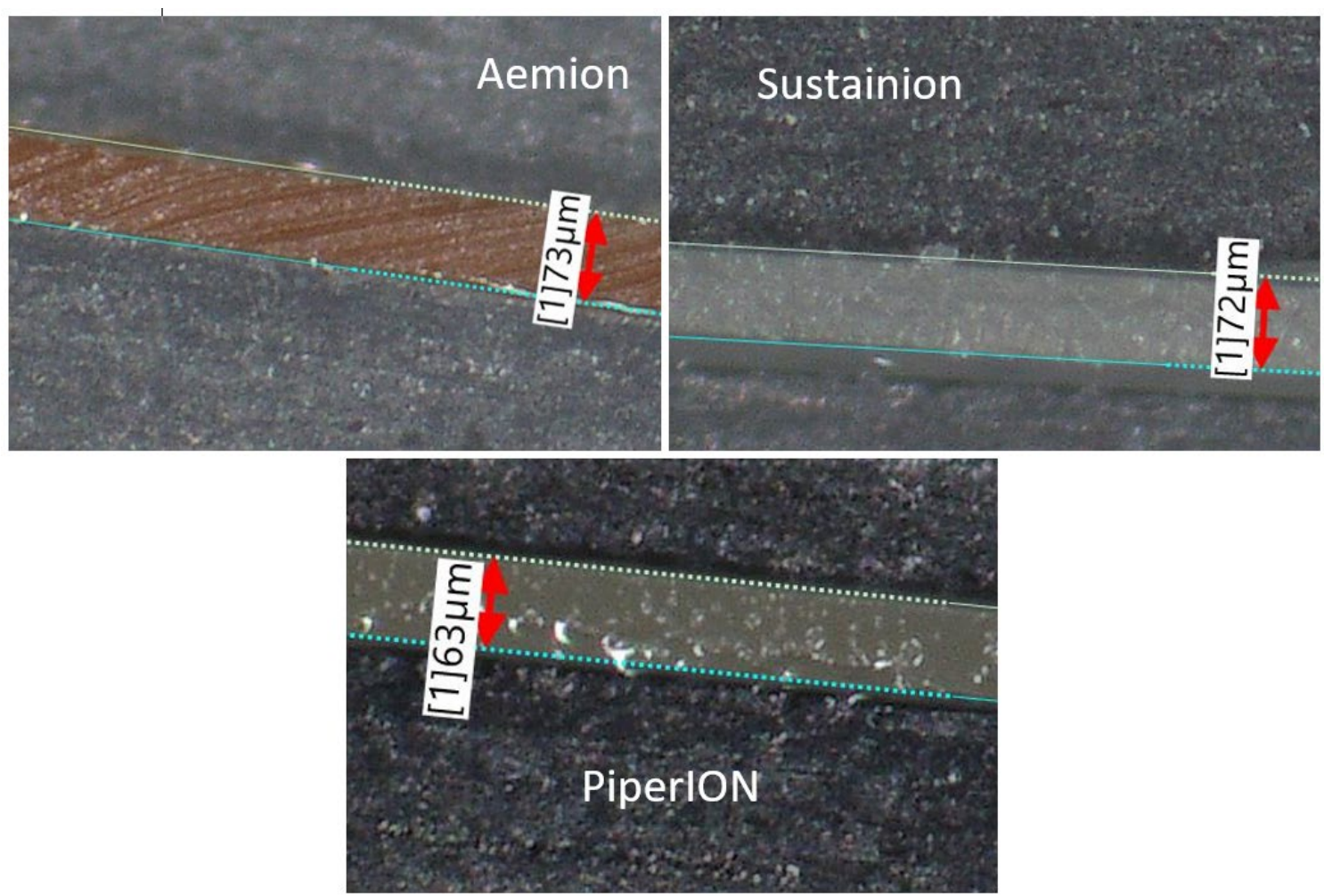

Figure S3: Thickness of membranes hydrated in $\mathrm{KOH}$. Membranes were clamped between two glass slides and thickness measured with a Keyence VHX 7000 digital microscope.

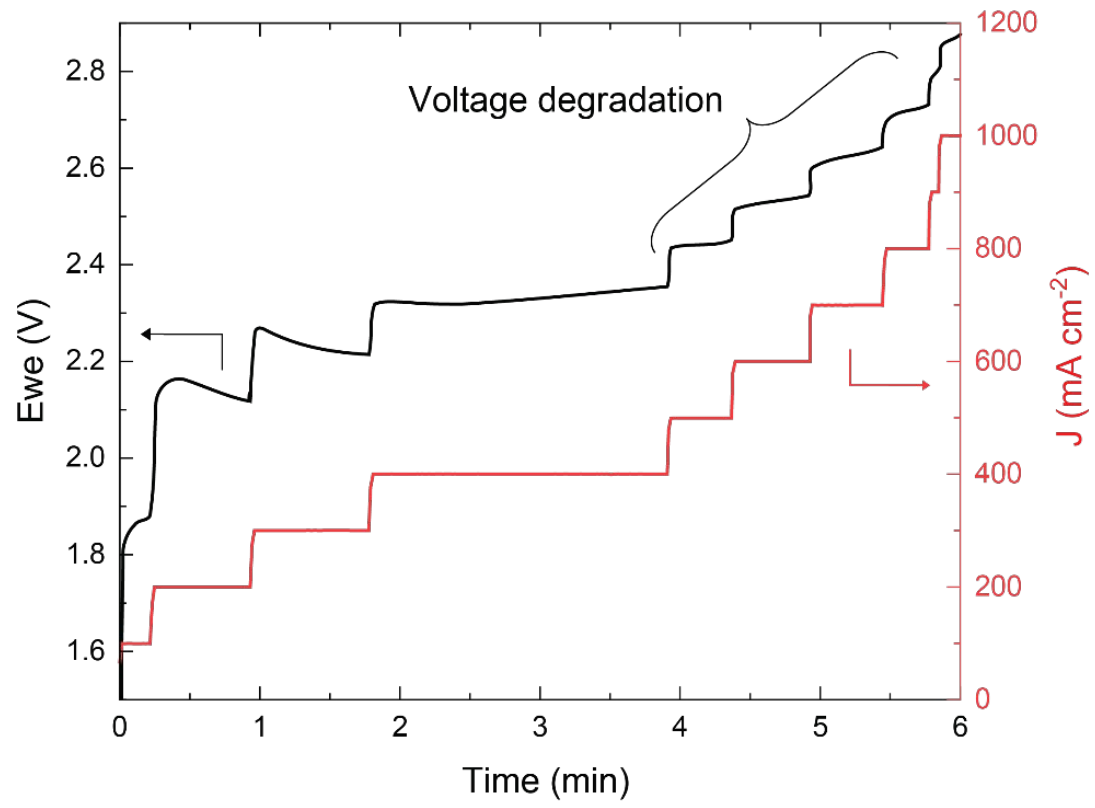

Figure S4: Aemion operation at $69^{\circ} \mathrm{C}$. The high temperature causes the membrane to break down, as is observed by the voltage degradation (as opposed to the expected stabilization) at each current step. 


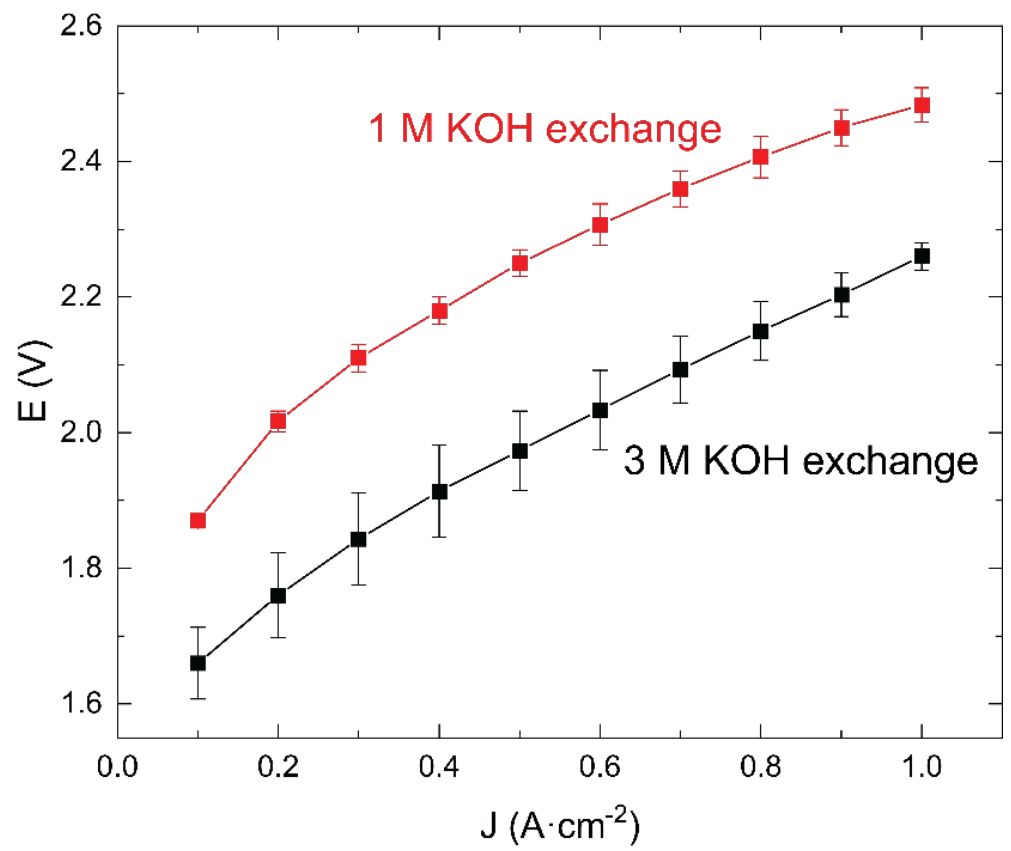

Figure S5: Effect of ion exchange on Aemion operation. Significant performance enhancements were observed when pre-soaking the membrane in $3 \mathrm{M} \mathrm{KOH}$ (black) versus $1 \mathrm{M} \mathrm{KOH}$ (red), showing the importance of sufficiently exchanging $\mathrm{OH}^{-}$for $\mathrm{I}^{-}$in the membrane.

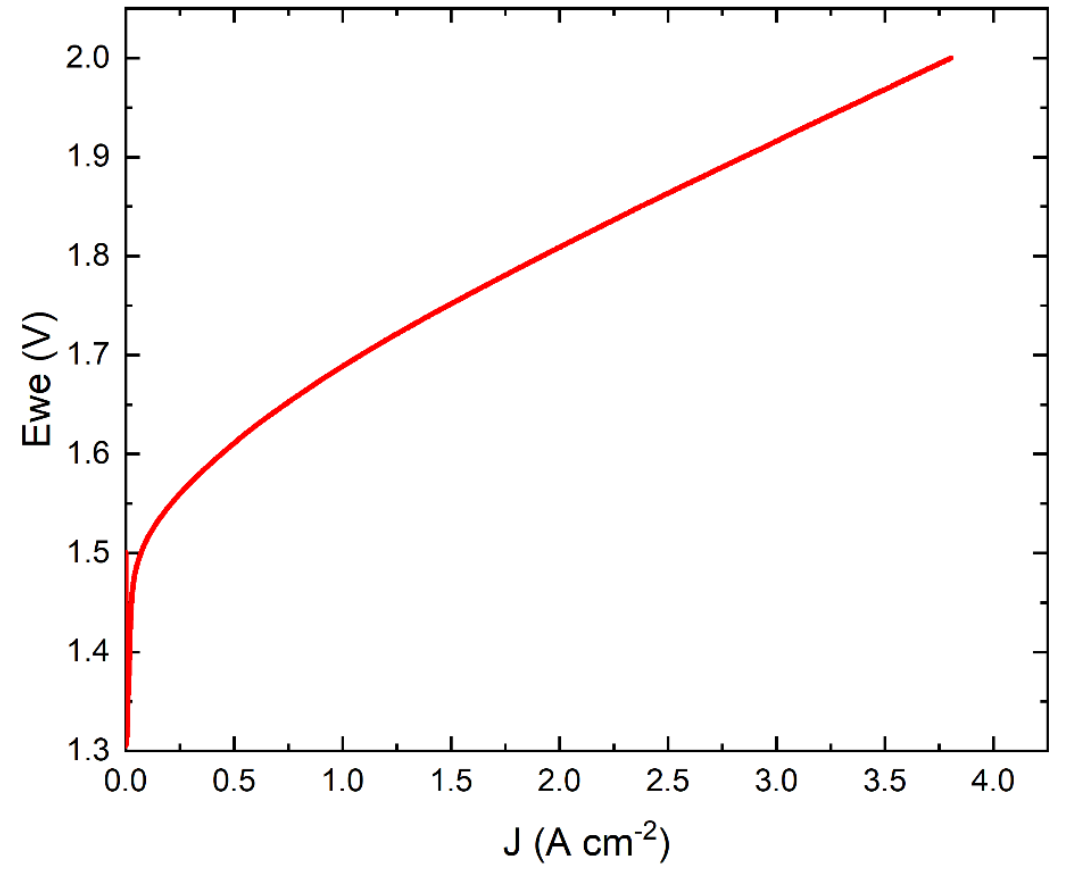

Figure S6: Polarization curve of AEM electrolyzer prepared with baseline materials in $1 \mathrm{M} \mathrm{KOH}$ at $55 \pm 1{ }^{\circ} \mathrm{C}$. 


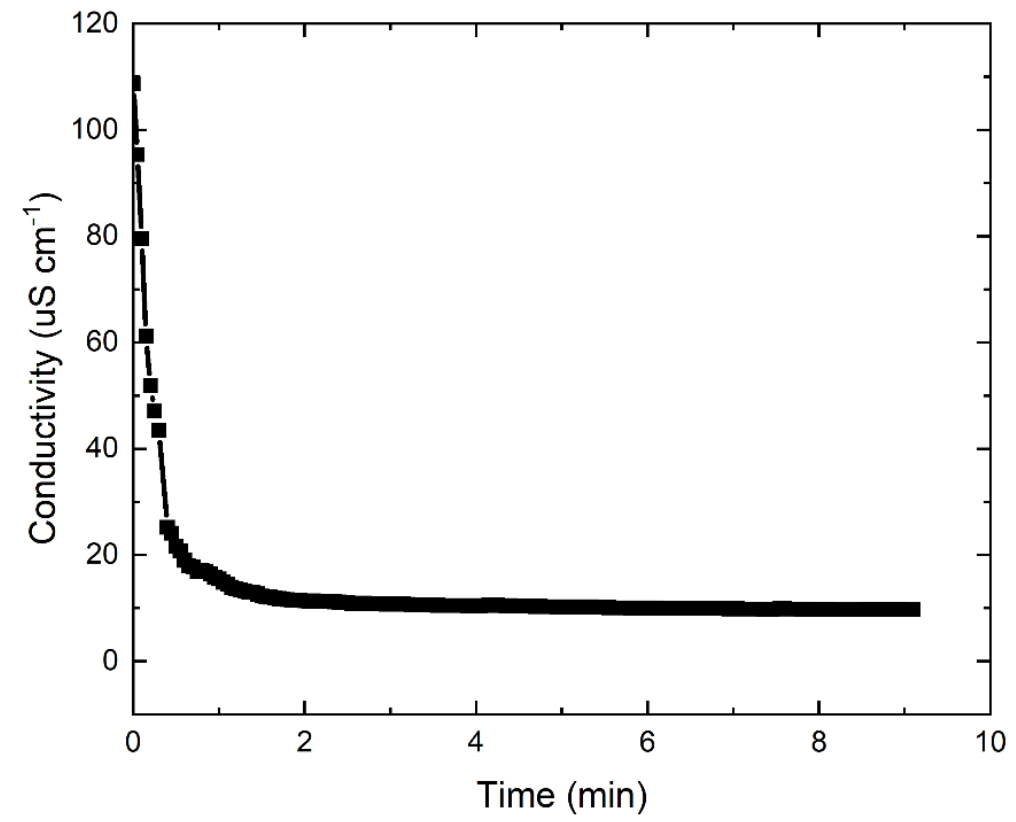

Figure S7: Conductivity of effluent electrolyte measured after the initial $500 \mathrm{~mL}$ of water had been purged through the electrolyzer.

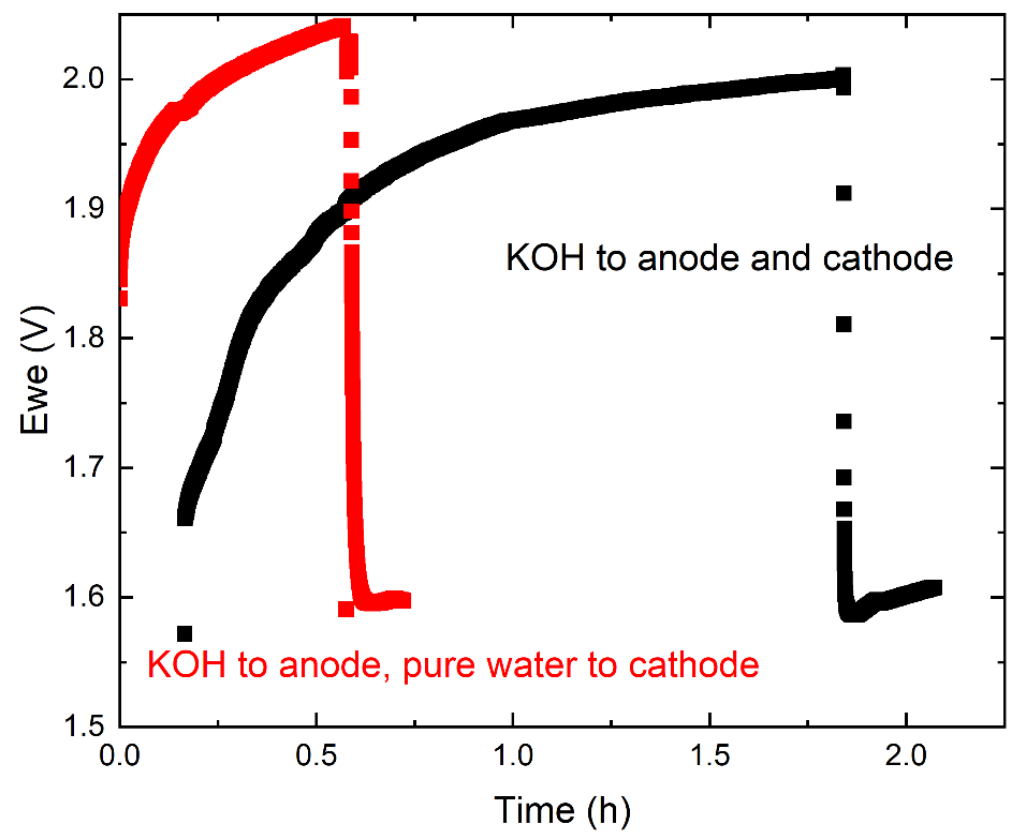

Figure S8: Changes in degradation behavior in pure water and $\mathrm{KOH}$. The cell was operated at $55 \pm 1{ }^{\circ} \mathrm{C}$. After conditioning in pure water, the cell was operated at $500 \mathrm{~mA} \cdot \mathrm{cm}^{-2}$ and the voltage degradation observed. The anode and cathode streams were then switched to $1 \mathrm{M} \mathrm{KOH}$ at the same temperature (black). Water was then purged to the system for $>10 \mathrm{~min}$, or $>5 \mathrm{~L}$ of water. The same cell was then again operated at $500 \mathrm{~mA} \cdot \mathrm{cm}^{-2}$ in pure water, then 1 $\mathrm{M} \mathrm{KOH}$ was added only to the anode stream maintaining pure water at the cathode (red). 


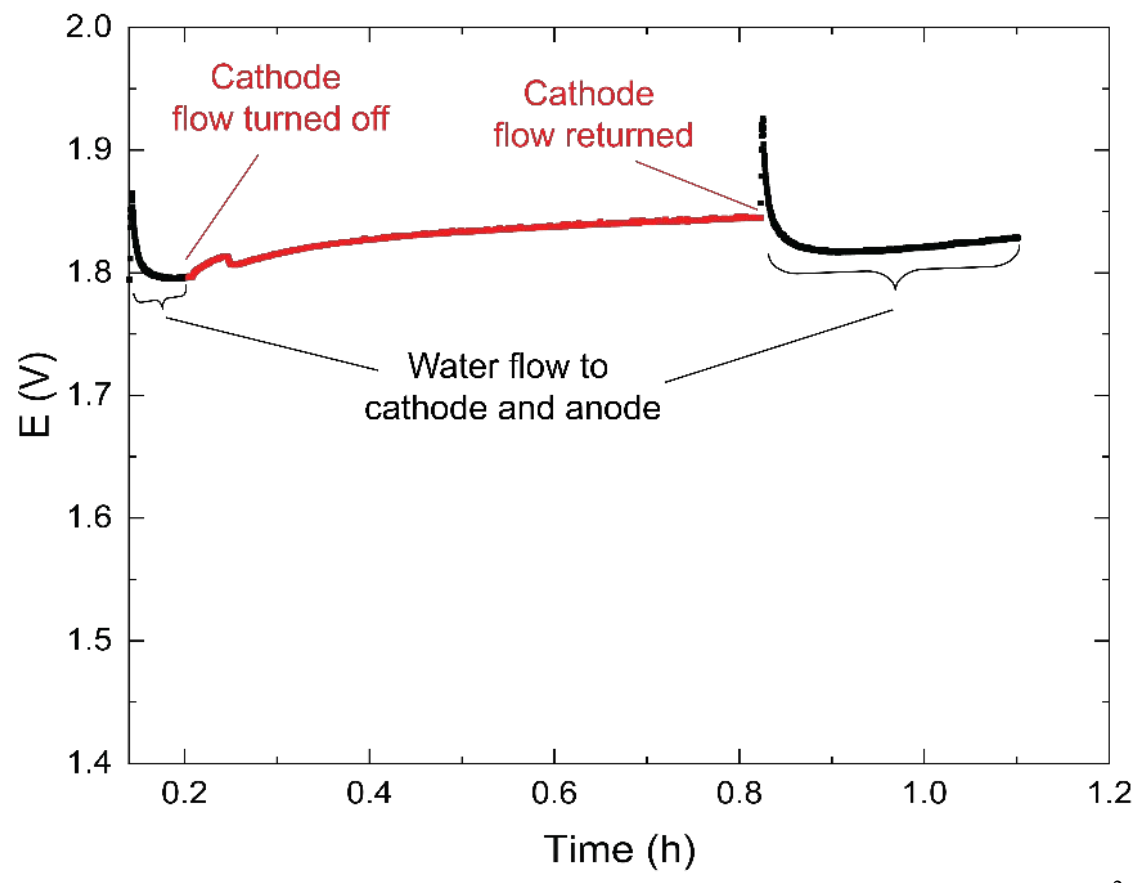

Figure S9: Performance with different water feed modes. The cell was operated at $500 \mathrm{~mA} \cdot \mathrm{cm}^{-2}$ at $69 \pm 1{ }^{\circ} \mathrm{C}$ with water flowing to both the cathode and the anode. Water flow to the cathode was turned off and voltage degradation was observed before stabilizing (note - the small voltage recovery at approximately $0.3 \mathrm{~h}$ is attributed to water diffusing from the anode to the cathode after flow was turned off). After cathode flow was returned a partial voltage recovery was observed. 